\title{
CASE STUDY ON A BUILDING CONSTRUCTION PROJECT CARRIED OUT USING A "COOPERATIVE VENTURES" APPROACH
}

\author{
S. FURUSAKA \\ Dept. of Architecture and Architectural Systems, Kyoto University, Kyoto, Japan \\ T. TAIRA \\ ADMIX Co. Ltd., Tokyo, Japan
}

M. MATSUMOTO

Marketing Dept., Hankyu Corporation, Osaka, Japan

\begin{abstract}
This paper reports on the use of a "Cooperative Ventures" approach to execute a construction project. As demonstrated in this case study, the proposed method is potentially a practical means for project implementation. The effectiveness of this method is examined through a case study in which the project planning and design phases are compared.

Keywords: cooperative venture, decision making, simultaneous engineering, Fuzzy Interpretive Structural Modeling, FISM, Analytic Hierarchy Process, AHP, organization design
\end{abstract}

Keywords: cooperative Venture, decision making, simultaneous engineering, AHP

\section{INTRODUSTION}

Recently, building construction projects in Japan have become more complex in various aspects. The main reasons are increase of the amount of information, progress of the information technology, diversification of the construction technologies and specialization of works. Furthermore, project participants' behavior has clearly changed in that the owners and the facility users have come to participate more positively in the entire process.[1][2] They have come to discuss the projects at each stage of programming, design and construction. The engineers involved at the design stage or at the construction stage also are contributing to propose different technologies and their know-how more positively.

On the other hand, the Japanese construction industry has experienced failure in the promotion of certain types of projects, particularly in the construction of publicly funded projects such as city halls, parks and citizen's centers. Various problems have lead these projects failure. For example, problems such as regional residents opposition, lack of technical and economical feasibility studies and budget excesses have occured at the stages where the project moves from programming to construction.

These unsuccesful experiences in public projects suggest that there exists the necessity of adopting requirements of users' as well as technical opinions of expert engineers positively during the project programming stage.

To incorporate these inputs into the project, a new method of project management is needed. The method must take into consideration these aforementioned needs, existing information and technologies about the project, and must use technologies, know-how, and the requirements of all the people related to the project.

The purposes of this paper are: (1) to propose and discuss an implementation method for cooperative ventures in construction projects (hereinafter, to be called, "Cooperative Ventures"), and (2) to examine the effectiveness of this method through a case study of its implementation in a specific "experimental" project. To achieve these purposes, the following steps were taken:

1) Definition of concepts and mechanisms of the "Cooperative Ventures" method;

2) Application of "Cooperative Ventures " to the project;

3) Application of decision support methods to implement the "Cooperative Ventures "

4) Assessment of the effectiveness of the method and identification of any "problems" 
Therefore, it would be useful to define the procedure of the implementation. The procedure applied in the experimental project are as follows.

Procedure 1: The purpose of the project is identified.

Procedure 2: The participants' list and the method for decision making are selected.

Procedure 3: Existing problems are investigated and their solutions are extracted through group discussions

Procedure 4: The direction of project programming is approved.

Procedure 5: New solutions are collected from participants in the consultation process

Procedure 6: Interested parties confer on the collected ideas, and formulate basic project concepts

Procedure 7: The team formulating the schematic design is organized according to each basic project concept. Suitable members are selected for each basic project concept; normally the team includes the designer, the contractor, the user, etc. It is critical to select the correct individual with the proper credentials as the team leader.

Procedure 8: The schematic designs are presented to the users and regional residents and the designs are evaluated from numerous viewpoints. (This is termed the fixation of the schematic design adopting)

Procedure 9: The Schematic design are finalized and the execution design is started (henceforth omission).

\subsection{Features of "Cooperative Ventures"}

"Cooperative Ventures" possesses the following two features:

1) "Cooperative Ventures" is composed of interested individuals all possessing knowledge about different technology and having different know-how. The parties that participate in the consultation process can include: the owners, local governments, users, regional residents, specialty consultants, civil engineers, architects, general contractors and specialty contractors.

2) In the building construction process, all interested parties participate at a required stage or activity for the project; each contributor's abilities are drawn out to their maximum; consensus is developed by comparing individual objectives to the project purpose, and consensus is achieved by adjusting individual interests to reach agreement in principal on the overall project objectives. This process requires that comparative studies of alternative approaches are performed, and thereby the best alternative is selected

\section{INPLEMENTATION OF COOPERATIVE VENTURES"}

\subsection{Outline of project}

Kyoto City is one of the oldest towns in Japan. The central part of the city has prospered for centuries. However, the new towns in the surrounding area are now part of the city, and the commercial facilities have continued to increase in the centre of Kyoto. This tends to decrease the population in the central area. This demographic shift has created problems for many sectors of the population including the school system, more specifically the unification and reorganization of elementary school in Kyoto City. A case study is presented for a school in the central area.

The area of the site for the case study project is $6,468 \mathrm{~m}^{2}$. The site consists of an elementary school which is adjoined to a kindergarden and children's park. The elementary school was scheduled for demolition and this posed the question, "what is the reuse of this site?" The "Cooperative Ventures" approach was experimentally used to solve this problem. The case study focuses on the period from the stage of the basic project concept planning stage to the stage where the schematic design for the project is completed.

\subsection{Execution procedure of experimental project}

The experimental project was executed according to the procedures illustrated in Figure 3. The detail of each procedure is as mentioned in 2.3.

\section{MAIN IDEAS ADOPTED IN "COOPERATIVE VENTURES"}

In this "Cooperative Ventures" project, several decision making methods were found to be effective. In this paper, two methods are explained,which are "Identification of purposes" and AHP[3].

\subsection{Identification of purposes}

In this "Cooperative Ventures " project, the most significant objective was assumed to be "Reasonable promotion of the project." The authors developed five ways to achieve this objective.

They are: (1) specifying the decision making process, (2)increasing the degree of satisfaction of participants,(3) shortening the project duration, (4) providing security for correspondence, (5) improving the concept. 


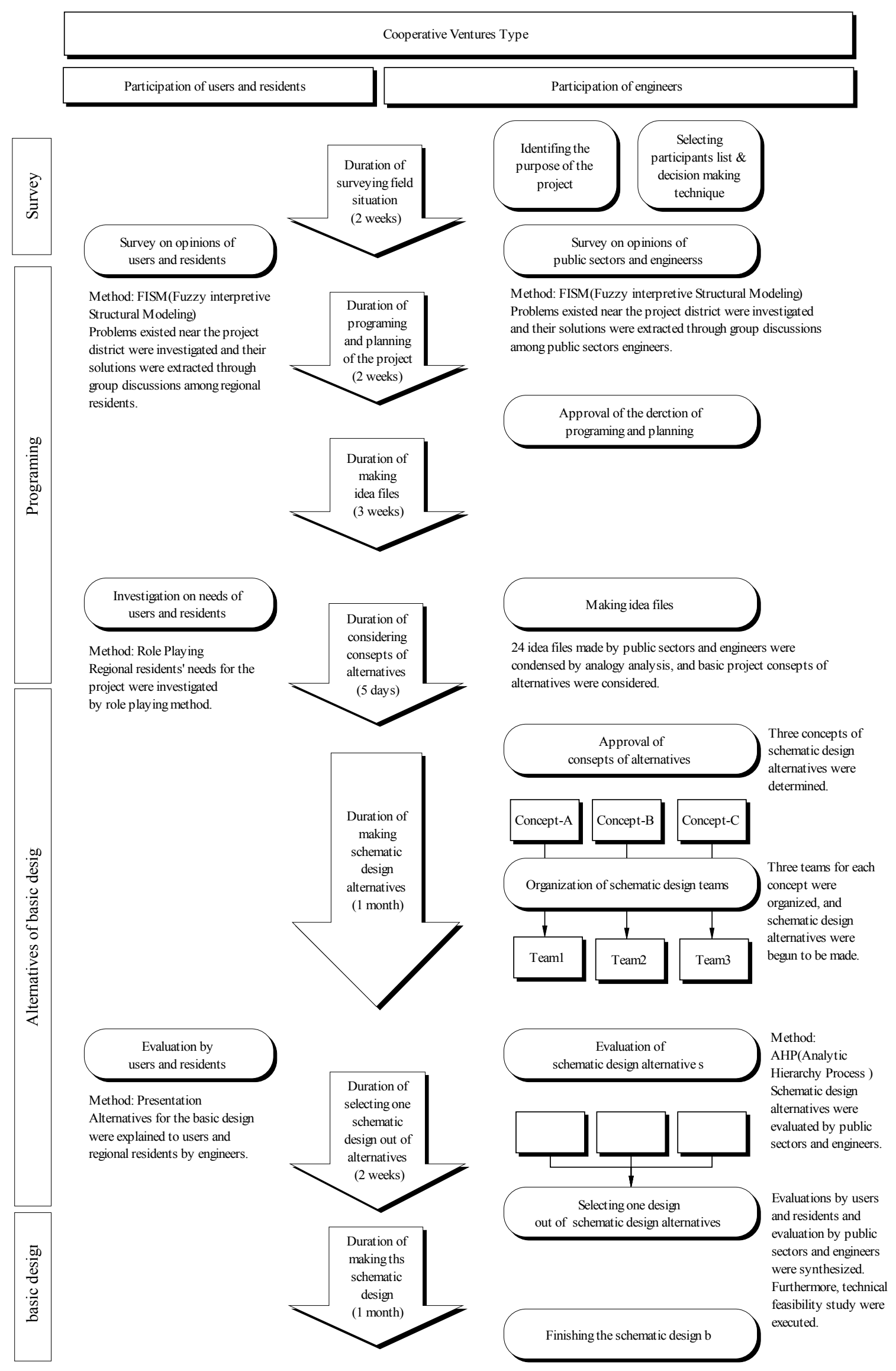

Figure 3. Job flow of the experimental project 
There teams are identified to achieve these aforementioned goals. They had to:

(1) understand the problem and the solution,

(2) start decision making only when mutual agreement was obtained,

(3) establish rules for decision making and

(4) share understanding among all members in the development of specifications for the decision making process.

In addition, the teams deliberated about

(1) specifying the decision making methods,

(2) presentation of the content which had to decide the intention,

(3) clarification of the criterion in the achievement of

(4) developing the rules for decision making.

The methods such as AHP and ISM[4] are more suited to identify the specification of the decision making methods. Thus, the layered structure shown in Figure 4 was developed to show the linkages between purposes and the means to achieve the project objectives.

\section{$4.2 \mathrm{AHP}$}

\subsubsection{About AHP}

The decision-making problem here is to organaize relationship among "Purpose", "Evaluation item" and "Alternative idea". The alternative ideas are compared respectively from the viewpoint of each evaluation item and the evaluation items are compared respectively from the viewpoint of the purpos. As a result, the alternative ideas from the viewpoint of the purpose can be evaluated by using the results of the previous comparisons. It is effective to the fixed quantity of a subjective judgment of complex, vague man. The result of AHP is shown in Figure 5 and Table 1.
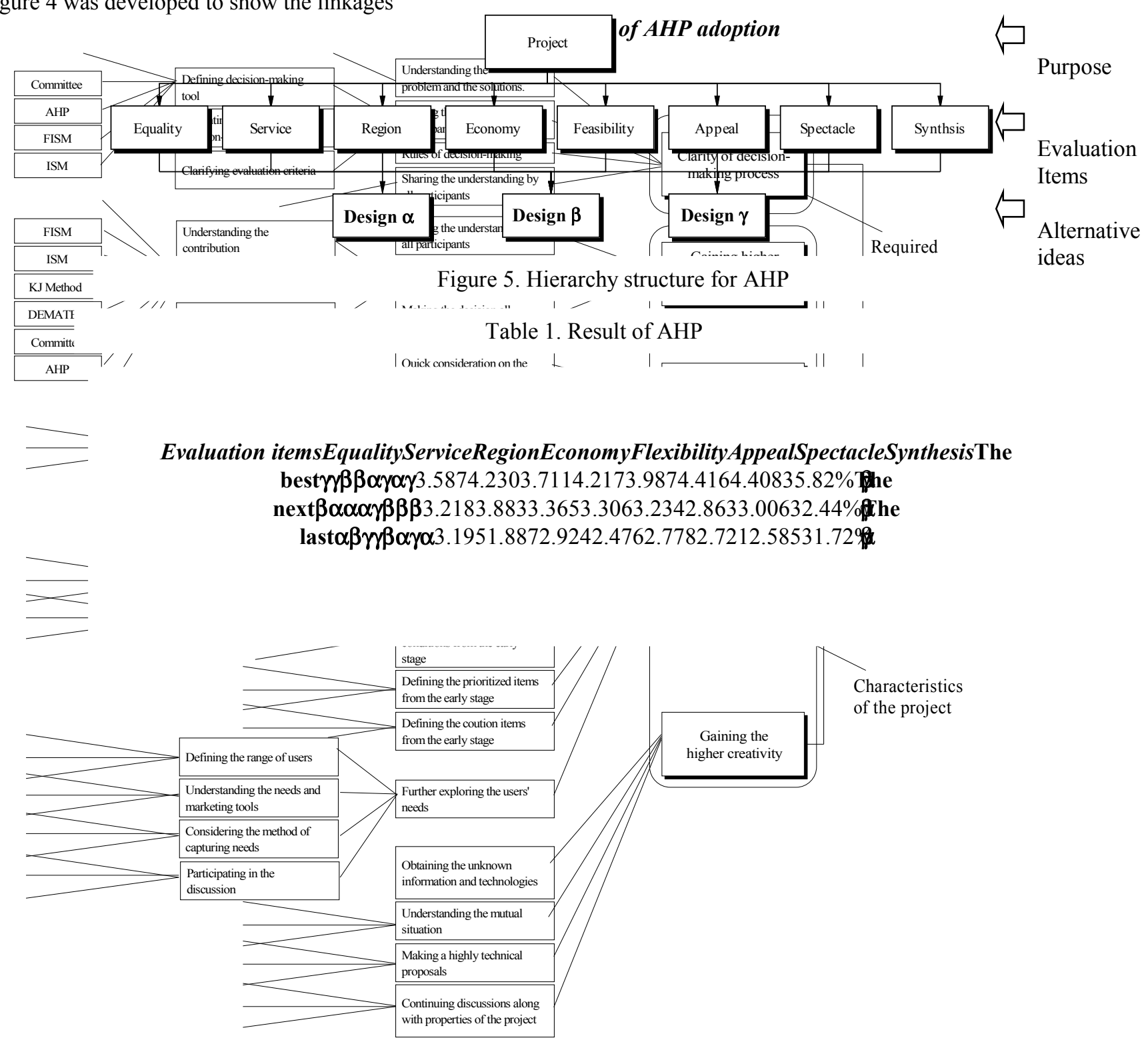

Figure 4. Objectives of the Cooperative Ventures building construction project 
1) Selection of the schematic designs $(\alpha, \beta$ and $\gamma)$

2) Understanding of the selection process of the suitable schematic design

\subsubsection{Results}

1) The evaluation items were specified, and it was possible to evaluate the schematic designs quantitatively. Therefore, the schematic design selection process became clear and objective. 2) The decision making and the mutual agreement formation by the group was facilitated.

\section{CONCLUSION}

In this paper, a "Cooperative Ventures" approach was proposed and a case study was conducted to ascertain the effectiveness of this method.

The evident advantages using this approach are as follows.

1) Special knowledge obtained form various participants can be used at any stages.

2) Decision making methods are effective for having concensus among the participants. Especifically, AHP and organization design are very effective.

3) The typical subjective decision making becomes more objective with the use of these methods.

The followings are the itmes that are though to refine a "Cooperative Ventures" methods.

1) Considerable time is required for discussion, analysis and evaluation - alternate means should be investigated to minimize this time requirement when implementing the current method.

2) When implementing a "Cooperative Ventures" project, the success of the implementation is highly dependent on the ability of the project manager to adequately promote the method to those involved in the work.

\section{Acknowledgments}

While undertaking this research, the authors were fortunate to obtain considerable cooperation from the local government as well as the regional residents of Kyoto City and the construction industry. For this singular cooperation, we wish to express our sincere gratitude.

\section{REFERENCES}

[1] James L. Creighton, "Public Involvement", Abt Books, 1981.

[2] Asami Yoshiharu, Ito Masaharu et. al. "Sanka no Dezain Dougubako", Setagaya-Machizukuri-Center, 1993.

[3] Thomas. L. Saaty, "Analilic Hierarchy Process", McgGROW-HILL, 1980.

[4] Warfield, J., "Toward Interpretation of omplex Structural Modeling", IEEE Transaction Systems,
Man, and Cybernetics, Vol. SMC-, No.5, September pp.405-417 